\title{
INFLUÊNCIA DO TEMPO DE DETENÇÃO HIDRÁULICA EM UM SISTEMA UASB SEGUIDO DE UM REATOR BIOLÓGICO COM FUNGOS PARA TRATAR EFLUENTES DE INDÚSTRIA DE CASTANHA DE CAJU
}

\section{INFLUENCE OF THE TIME OF DETENTION HIDRAULIC OF A SISTEM UASB FOLLOWED BY A BIOLOGICAL REACTOR WITH FUNGI TO TREAT EFLUENT OF CASHEW NUT INDUSTRY}

\begin{abstract}
EMÍlLIA Maria ALVES SANTOS
Professora do Centro Federal de Educação Tecnológica do Ceará. Doutoranda em Engenharia Civil - Área de Saneamento Ambiental (UFC)
\end{abstract}

\section{GLória Maria Marinho Silva Sampaio}

Professora do Centro Federal de Educação Tecnológica do Ceará. Doutora em Hidráulica e Saneamento (EESC - USP)

\section{RENATO CARRHÁ LEITÃO}

Engenheiro Civil pela UFC. Doutor em Tecnologia Ambiental pela Universidade de Wageningen - Holanda

$$
\text { ANDRÉ MACÊDO FACÓ }
$$

Mestre em Engenharia Civil - Área de Saneamento Ambiental (UFC)

\section{EVERARDO ALBUQUERQUE MENEZES}

Professor de Microbiologia do DACT/FFOE/UFC. Doutor em Microbiologia pela USP

\section{SANDRA TÉDDE SANTAELLA}

Professora Adjunta do Departamento de Engenharia Hidráulica e Ambiental da Universidade Federal do Ceará

Recebido: 13/10/05 Aceito: 08/01/06

\section{RESUMO}

Nesta pesquisa, estudou-se a influência do tempo de detenção hidráulica (TDH) em um sistema constituído de um reator anaeróbio tipo UASB seguido de um reator biológico com fungos $(\mathrm{RBF})$ para tratar efluente de uma indústria de beneficiamento de castanha de caju. O presente trabalho foi dividido em uma fase de fluxo descontínuo (batelada) e uma fase de fluxo contínuo (UASB - RBF), que constituiu-se de sete etapas ( $8 \mathrm{~h}$ e $2 \mathrm{~h}$, $8 \mathrm{~h}$ e $1 \mathrm{~h}, 4 \mathrm{~h}$ e $8 \mathrm{~h}, 4 \mathrm{~h}$ e $6 \mathrm{~h}, 4 \mathrm{~h}$ e $4 \mathrm{~h}, 4 \mathrm{~h}$ e $2 \mathrm{~h}$ e $4 \mathrm{~h}$ e $1 \mathrm{~h}$ ), onde foi avaliada a influência do TDH na remoção de: DQO (Demanda Química de Oxigênio), amônia, nitrato e ortofosfato. Uma combinação que apresentou melhores resultados, foi a etapa de $4 \mathrm{~h}$ (TDH do reator UASB) e $2 \mathrm{~h}$ (TDH do $\mathrm{RBF}$ ), apresentando remoçôes de: $93,8 \%$ de DQO, 86,7\% de nitrato, 38,3\% de amônia e $16 \%$ de ortofosfato.

PALAVRAS-CHAVE: Reator biológico com fungos, UASB, tempo de detenção hidráulica.

\begin{abstract}
In this research, it was studied the effect of hydraulic retention time (HRT) in a system comprised of an Upflow Anaerobic Sludge Blanket (UASB) reactor and a Biological Reactor with Fungi (BRF) for treatment of the efluent of the industry of cashew nut improvement. The work was divided in two phases: batch reactors using shaking flasks and continuous-feed reactors (UASB-BRF). The UASB reactor was operated at $H R T$ of 4 and $8 \mathrm{~h}$, whereas the BRF was operated at $H R T$ varying from 1 to $8 \mathrm{~h}$. The performance of both reactors was evaluated based on the removal efficiency of chemical oxygen demand (COD), ammonium, nitrate, and orthophosfate. The results show that the best results were achieved when the UASB was operated at $H R T$ of $4 h$ and the BRF was operated at HRT of $2 h$, when the system removed $93,8 \%$ of the COD, $86,7 \%$ of the nitrate, $38,3 \%$ of the ammonium and $16 \%$ of the orthophosfate.
\end{abstract}

KEYWORDS: Biological reactor with fungi, UASB, hydraulic hold time. 


\section{INTRODUÇÃO}

O beneficiamento da castanha de caju é uma das atividades industriais de maior importância nos Estados do Nordeste Brasileiro. Devido a essa intensa atividade produtiva, essas indústrias são grandes geradoras de resíduos líquidos.

Tal efluente é potencialmente poluidor e é necessário que se aprimorem tecnologias e técnicas no sentido de tratálo adequadamente, a fim de minimizar os impactos de seu lançamento nos cursos d'água ou na rede coletora de esgoto. $\mathrm{O}$ tratamento anaeróbio e o tratamento com fungos têm despontado como alternativas eficientes para esses efluentes.

De acordo com Soares (1986), o processo de beneficiamento da castanha de caju envolve basicamente oito etapas: pesagem, armazenagem, secagem, classificação (separação das amêndoas de acordo com o tamanho), lavagem, extração do Líquido da Castanha de Caju - LCC (em temperatura de 200 a $220^{\circ} \mathrm{C}$ ) e descortinagem (quebra das amêndoas).

De acordo com Santaella et al (1999), os efluentes da indústria de beneficiamento de castanha de caju são gerados, em grande parte, nas etapas de lavagem e umidificação da castanha, lavagem dos equipamentos utilizados no processo e no lavador de gases.

Segundo Metcalf \& Eddy (1991), os processos aeróbios, anaeróbios e anóxicos são os principais processos de tratamento biológico de águas residuárias. Em muitas operaçôes, dependendo da finalidade a que se destina o efluente e da eficiência de remoção desejada, combinações entre os três processos são muito comuns.

Os fungos exercem papel importante dentro do saneamento, pois atuam nos processos de transformação dos resíduos orgânicos, onde funcionam como recicladores de matéria nos diversos ecossistemas.

O potencial fúngico para degradar polímeros tem sido amplamente estudado e em muitos casos aplicado para remoção de compostos de difícil degradação. Os fungos, de modo geral, promovem degradação de compostos aromáticos, via os sistemas enzimáticos citocromo P450 monoxigenase e lignolítico (Prenafeta Boldú, 2002).

Em vista disso, neste trabalho, foi avaliada a influência, em termos de tempo de detenção hidráulica (TDH), de um sistema constituído por um reator anaeróbio do tipo UASB, seguido de um reator biológico com fungos $(\mathrm{RBF})$ para tratar águas residuárias de uma indústria de beneficiamento de castanha de caju.

Foi avaliada a influência do TDH na remoção de: DQO (Demanda Química de Oxigênio), amônia, nitrato e ortofosfato nos reatores UASB e RBF separadamente e também no sistema. No reator UASB estudou-se também a remoção de Sólidos Suspensos Totais (SST).

A pesquisa constituiu-se de duas fases distintas: fase de fluxo descontínuo (batelada) e fase de fluxo contínuo (UASB - RBF), tendo sido esta última etapa uma continuidade do trabalho de Sampaio et al (2004), que em sua pesquisa estudaram etapas com tempos de detenção hidráulica mais elevados (12h e $4 \mathrm{~h}, 12 \mathrm{~h}$ e $2 \mathrm{~h}, 12 \mathrm{~h}$ e $1 \mathrm{~h}, 10 \mathrm{~h}$ e $4 \mathrm{~h}, 10 \mathrm{~h}$ e $2 \mathrm{~h}, 10 \mathrm{~h}$ e $1 \mathrm{~h}$ ).

\section{OBJETIVO}

Estudar a influência do Tempo de Detenção Hidráulica (TDH) de um sistema constituído por um reator anaeróbio do tipo UASB, seguido de um Reator Biológico com Fungos (RBF), inoculado com as espécies Aspergillus niger e Cladosporium herbarum, para tratar águas residuárias de uma indústria de beneficiamento de castanha de caju.

\section{MATERIAIS E MÉTODOS}

A água residuária foi coletada do tanque de equalização de uma indústria de beneficiamento de castanha de caju.

As espécies fúngicas Aspergillus niger e Cladosporium herbarum utilizadas nos experimentos foram captadas do próprio ar em placas de Petri com ágar Sabouraud e em seguida foram isoladas e incubadas em garrafas de Roux, em meio de cultura Sabouraud. À garrafa de Roux, com as referidas espécies, foi adicionado cloranfenicol para inibir a proliferação de bactérias. As espécies fúngicas permaneceram nesse meio durante 28 dias a fim de atingirem o crescimento desejado.

$\mathrm{Na}$ fase de fluxo descontínuo, foram utilizados 14 (quatorze) reatores aeróbios: frascos de vidro com capacidade para 3,5 L previamente esterilizados com luz ultravioleta. Tais reatores foram agrupados em lotes de acordo com o tempo de reação (4h; 8h; 20h; 1d; 2d; 4d; 8d). Cada lote era constituído de um reator de controle com 1,5 L de esgoto equalizado e um reator teste contendo um 1,75 L de esgoto equalizado, 4,7 $\mathrm{g}$ de inóculo fúngico e 0,05 g/L de cloranfenicol.
Imediatamente após a montagem de cada reator, foi retirada uma alíquota de $250 \mathrm{~mL}$ do reator teste e do reator de controle, a fim de se caracterizar o afluente do processo. À medida que foram sendo desmontados os reatores, de acordo com os seus tempos de reação (4h; $8 \mathrm{~h}$; 20h; 1d; 2d; 4d; 8d) foram sendo retiradas alíquotas para a caracterização do efluente.

Para a etapa de fluxo contínuo foi empregado: um reator UASB confeccionado em fibra de vidro, com volume útil de 4,0 L e comprimento total de $70,5 \mathrm{~cm}$, tendo suas extremidades inferior e superior formatos cônicos, e seu corpo um formato cilíndrico. O reator continha um separador de fases. Os diâmetros da parte superior, do separador de fases e do corpo do reator foram, respectivamente: $15,0 \mathrm{~cm}, 5,5 \mathrm{~cm}$ e $7,5 \mathrm{~cm}$. O reator biológico com fungos que sucedia o reator UASB também foi montado em fibra de vidro, possuía volume útil de 3,0 L, era dotado de entrada e saída para o efluente e dois dispositivos para fornecimento de ar, o qual foi fornecido por um aerador de aquário, durante todo o tempo de operação.

O lodo utilizado no reator anaeróbio era proveniente do fundo do tanque de equalização da estação de tratamento de esgoto (ETE) da própria indústria e foi aclimatado por 30 dias.

O meio suporte utilizado no reator aeróbio foi manta agulhada de poliamida, com 2,0 mm de espessura, massa específica de $0,023 \mathrm{~g} / \mathrm{cm}^{3}$ e diâmetro médio do fio de $0,31 \mathrm{~mm}$. A manta foi cortada em retângulos de $2 \times 3 \mathrm{~cm}$, lavada em água corrente, secada em estufa $\left(100^{\circ} \mathrm{C}\right)$ e agrupada em redes de polietileno. Foram confeccionados 8 saquinhos com 40 retângulos em cada um. A massa fúngica $(101,9 \mathrm{~g})$ foi inoculada entre os sacos de manta suporte, da qual, ao final do experimento, retirou-se uma amostra para a identificação qualitativa dos microrganismos presentes nesta. Considerando que a etapa de "fluxo contínuo" constituía-se de dois reatores em série, os tempos de detenção hidráulica foram estudados em etapas, ou seja, uma etapa de $8 \mathrm{~h}$ e $2 \mathrm{~h}$, significava um tempo de detenção hidráulica de $8 \mathrm{~h}$ para o reator anaeróbio e um tempo de detenção de $2 \mathrm{~h}$ para o RBF, perfazendo um total de 10 horas para o sistema UASBRBF. O presente trabalho constituiu-se de sete etapas: $8 \mathrm{~h}$ e $2 \mathrm{~h}, 8 \mathrm{~h}$ e $1 \mathrm{~h}, 4 \mathrm{~h}$ e $8 \mathrm{~h}, 4 \mathrm{~h}$ e $6 h, 4 h$ e $4 h, 4 h$ e $2 h, 4 h$ e $1 h$.

Após completar-se o tempo de detenção hidráulica de cada reator, eram re- 
tirados pontos amostrais do efluente a estes, até que fosse verificada a estabilidade de remoção dos compostos causadores de DQO, o qual serviu como parâmetro para avaliar a estabilidade de cada etapa. Os experimentos foram realizados em um período de 9 meses e não houve intervalo de tempo entre as etapas.

\section{RESULTADOS E DISCUSSÃO}

A cada coleta realizada na indústria o efluente era devidamente caracterizado, tendo sido obtido os seguintes valores médios: $\mathrm{DQO}(1401,6 \mathrm{mg} / \mathrm{L})$, amônia- $\mathrm{NH}_{3}$ $(21,6 \mathrm{mg} / \mathrm{L})$, nitrato $-\mathrm{NO}_{3}^{-}(1,9 \mathrm{mg} / \mathrm{L})$, ortofosfato - $\mathrm{PO}_{4}^{3-}(8,0 \mathrm{mg} / \mathrm{L})$, Sólidos Suspensos Totais - SST (487,5 mg/L).

Rabelo (1999) em sua pesquisa realizou caracterização desta mesma água residuária, obtendo os seguintes valores médios: DQO $(974,0 \mathrm{mg} / \mathrm{L})$, $\mathrm{PO}_{4}^{3-}(15,1 \mathrm{mg} / \mathrm{L}), \mathrm{NH}_{3}(7,2 \mathrm{mg} / \mathrm{L})$, $\mathrm{pH}^{4}(7,7), \mathrm{SS}(761,0 \mathrm{mg} / \mathrm{L}), \mathrm{ST}$ (1693,0 mg/L).

Santaella et al (1997), realizando pesquisas com o mesmo tipo de efluente obtiveram os seguintes valores médios quando da sua caracterização: DQO (951,0 mg/L), $\mathrm{NO}_{3}^{-}(20,1 \mathrm{mg} / \mathrm{L})$, $\mathrm{NH}_{3}(3,5 \mathrm{mg} / \mathrm{L}), \mathrm{PO}_{4}^{3-}(14,2 \mathrm{mg} / \mathrm{L}), \mathrm{pH}$ $(7,7)$, ST (1268,0 mg/L), STD (835 mg/L).

Os trabalhos citados apresentaram valores de DQO e de $\mathrm{pH}$ semelhantes aos obtidos na presente pesquisa. Porém, os valores das variáveis $\mathrm{NH}_{3}, \mathrm{NO}_{3}^{-}$e $\mathrm{PO}_{4}^{3-}$, apresentaram-se muito diferentes, principalmente as variáveis de nitrogênio $\left(\mathrm{NH}_{3} \mathrm{eNO}_{3}^{-}\right)$.

A amonificação pode ser a principal responsável pela grande quantidade de amônia no efluente desta indústria. $\mathrm{O}$ processo, que envolve a transformação dos compostos orgânicos de nitrogênio (principalmente proteínas) em formas inorgânicas (principalmente amônia), pode estar se processando no próprio tanque de equalização da indústria.

\section{Remoção de DQO}

Na operação em batelada, observouse remoção de $\mathrm{DQO}$ em todos os tempos de reação estudados, tanto nos reatores de controle como nos reatores contendo as espécies fúngicas. As remoçôes de DQO nos reatores de controle, correspondentes a cada tempo de reação foram: $8,1 \%$ (4h), 50,6\% (1d), 34,4\% (2d), 32,5\% (4d) e $37,1 \%(8 d)$.
A maior remoção de DQO obtida pelas espécies fúngicas foi de $45,2 \%$ no tempo de reação de $8 \mathrm{~d}$. Tal resultado indicou a viabilidade do uso das referidas espécies no sistema UASB-RBF.

Santaella et al (1999), tratando o mesmo tipo de efluente em ensaio de biodegradabilidade por fungos em reatores de fluxo descontínuo, obtiveram remoção de $76 \%$ de DQO somente após 7 dias de operação, tempo também considerado longo, muito embora a eficiência de remoção tenha sido mais acentuada que na presente pesquisa.

$\mathrm{Na}$ fase de fluxo contínuo, observou-se no reator UASB, em quase todas as etapas estudadas ( $8 \mathrm{~h}$ e $2 \mathrm{~h}$, $8 \mathrm{~h}$ e $1 \mathrm{~h}, 4 \mathrm{~h}$ e $8 \mathrm{~h}, 4 \mathrm{~h}$ e $6 \mathrm{~h}, 4 \mathrm{~h}$ e $4 \mathrm{~h}, 4 \mathrm{~h}$ e $2 \mathrm{~h}$, $4 \mathrm{~h}$ e $1 \mathrm{~h}$ ), um acréscimo do $\mathrm{pH}$ efluente em relação ao $\mathrm{pH}$ afluente, estando para o primeiro, todos os valores obtidos em uma faixa favorável ao processo de digestão anaeróbia. Tal fato foi comprovado pela remoção de DQO neste reator.

Ocorreu remoção de DQO em todas as etapas estudadas neste reator (8h e $2 \mathrm{~h}, 8 \mathrm{~h}$ e $1 \mathrm{~h}, 4 \mathrm{~h}$ e $8 \mathrm{~h}, 4 \mathrm{~h}$ e $6 \mathrm{~h}, 4 \mathrm{~h}$ e $4 \mathrm{~h}$, $4 \mathrm{~h}$ e $2 \mathrm{~h}, 4 \mathrm{~h}$ e $1 \mathrm{~h}): 64,8 \%, 60,6 \%$, $48,1 \%, 82,9 \%, 54,8 \%, 68,9 \%$ e $69,0 \%$, respectivamente.

A maior eficiência de remoção de DQO, considerando o sistema (UASB$\mathrm{RBF}$ ) como um todo, foi de $93,8 \%$ na etapa de $4 \mathrm{~h}$ e $2 \mathrm{~h}$. As demais remoçōes ficaram em uma faixa de $75,0 \%$ a $93,0 \%$ o que comprovou a eficiência do conjunto na degradação da água residuária. Sampaio et al (2004), utilizando os mesmos reatores, obtiveram remoção em torno de $95 \%$ na etapa de $10 \mathrm{~h}$ e $4 \mathrm{~h}$. Ou seja, ocorreu na presente pesquisa, uma diminuição do TDH do sistema UASB - RBF, de $14 \mathrm{~h}$ para $6 \mathrm{~h}$, comprovando dessa forma, influência do TDH para remoção de DQO.

$\mathrm{Na}$ Figura 1 está indicada a variação de DQO para o sistema UASB-RBF, ao longo das etapas estudadas.

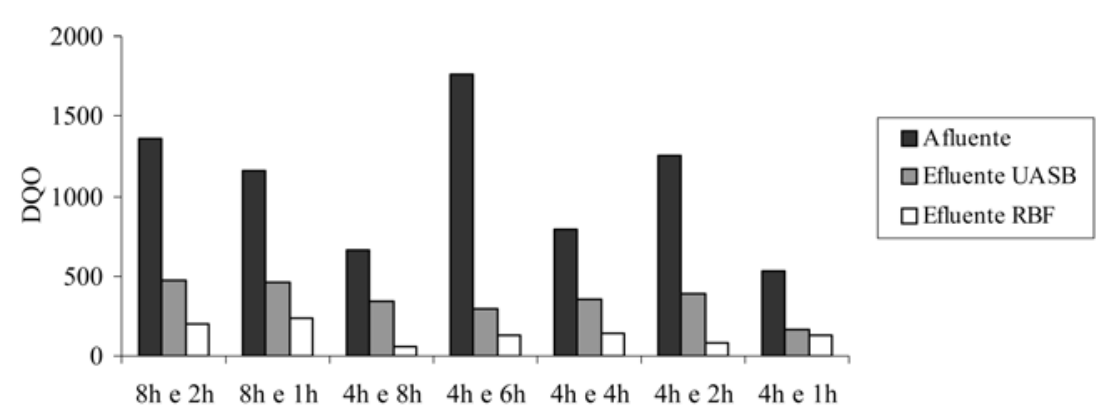

Etapas de TDH (h)

Figura I - Variação de DQO ao longo dos tempos de detenção hidráulica para o sistema UASB-RBF 
Tabela I - Média e desvio padrão dos valores de DQO

\begin{tabular}{|c|c|c|c|c|c|c|c|}
\hline UASB & $\begin{array}{c}\text { Entrada } \\
(\mathrm{mg} / \mathrm{L})\end{array}$ & $\begin{array}{l}\text { Media dos } \\
\text { pontos } \\
\text { efluentes } \\
(\mathrm{mg} / \mathrm{L})\end{array}$ & $\begin{array}{l}\text { Desvio } \\
\text { padrão }\end{array}$ & $\mathrm{RBF}$ & $\begin{array}{c}\text { Entrada } \\
(\mathrm{mg} / \mathrm{L})\end{array}$ & $\begin{array}{l}\text { Média dos } \\
\text { pontos } \\
\text { efluentes } \\
(\mathrm{mg} / \mathrm{L})\end{array}$ & $\begin{array}{l}\text { Desvio } \\
\text { padrão }\end{array}$ \\
\hline Anaeróbio $8 \mathrm{~h}$ & 1363,3 & 479,0 & 24,9 & Aeróbio $2 \mathrm{~h}$ & 596,7 & 204,3 & 5,4 \\
\hline Anaeróbio $8 \mathrm{~h}$ & 1163,0 & 457,7 & 14,2 & Aeróbio $1 \mathrm{~h}$ & 646,7 & 236,7 & 5,7 \\
\hline Anaeróbio $4 \mathrm{~h}$ & 660,0 & 342,7 & 56,8 & Aeróbio 8h & 359,3 & 64,9 & 15,9 \\
\hline Anaeróbio $4 \mathrm{~h}$ & 1760,0 & 300,0 & 12,5 & Aeróbio $6 \mathrm{~h}$ & 342,7 & 126,7 & 16,5 \\
\hline Anaeróbio $4 \mathrm{~h}$ & 793,3 & 358,7 & 27,2 & Aeróbio $4 \mathrm{~h}$ & 386,0 & 144,5 & 36,9 \\
\hline Anaeróbio 4h & 1260,0 & 391,3 & 17,7 & Aeróbio $2 \mathrm{~h}$ & 396,0 & 77,7 & 22,5 \\
\hline Anaeróbio $4 \mathrm{~h}$ & 526,7 & 163,3 & 4,4 & Aeróbio $1 \mathrm{~h}$ & 172,7 & 128,7 & 11,2 \\
\hline
\end{tabular}

Tabela 2 - Carga orgânica afluente e efluente ao sistema UASB-RBF e porcentagem de remoção de carga

\begin{tabular}{cccc}
\hline Etapas & $\begin{array}{c}\text { Carga afluente } \\
\text { ao sistema UASB-RBF } \\
(\mathrm{mg} / \mathrm{h})\end{array}$ & $\begin{array}{c}\text { Carga efluente } \\
\text { ao sistema UASB-RBF } \\
(\mathrm{mg} / \mathrm{h})\end{array}$ & $\begin{array}{c}\text { Procentagem de } \\
\text { remoção de } \\
\text { carga }(\%)\end{array}$ \\
\hline 8h e 2h & 681,6 & 306,4 & 55,0 \\
8h e 1h & 581,5 & 71,0 & 87,8 \\
4h e 8h & 660,0 & 24,3 & 96,3 \\
4h e 6h & 1760,0 & 63,3 & 96,4 \\
4h e 4h & 793,3 & 108,4 & 86,3 \\
4h e 2h & 1260,0 & 116,5 & 90,7 \\
4h e 1h & 526,7 & 386,1 & 26,7 \\
\hline
\end{tabular}

sendo utilizado como receptor de elétrons, o que implica em um processo de desnitrificação.

A temperatura, embora não tenha sido medida dentro do reator, estima-se que estivesse em uma faixa de $20^{\circ} \mathrm{C}$ a $30^{\circ} \mathrm{C}$, considerando que a temperatura do laboratório onde se processaram os experimentos era ambiente, o que reforça a ocorrência do processo de desnitrificação neste reator. No trabalho desenvolvido por Santaella et al (1999) utilizando reator UASB, a eficiência média remoção de nitrato foi de $74 \%$.

No RBF ocorreu remoção de nitrato nas etapas $58,3 \%$ ( $8 \mathrm{~h}$ e $2 \mathrm{~h}$ ); $40,6 \%$ (8h e $1 \mathrm{~h}$ ); 61,0\% (4h e $6 \mathrm{~h}$ ); 35,9\% (4h e $2 \mathrm{~h}$ ); $16,0 \%$ (4h e $1 \mathrm{~h}$ ). Nas demais etapas ocorreu um aumento na concentração de nitrato efluente em relação à concentração afluente.

Sá (1997), tratando água residuária de laticínio utilizando fungos decompositores, com tempos de detenção hidráulica de 31 e 21 h, obteve remoções máximas de nitrato de $50,0 \%$ e $37,5 \%$, res- pectivamente, tendo sido observado acúmulo do mesmo em vários períodos de sua pesquisa.

Rodrigues (1999), em seus experimentos, com água residuária sintética de laticínio, observou remoção média desta variável da ordem de 37,0\% para o tempo de detenção hidráulica de $31 \mathrm{~h}$, ao passo que para o tempo de detenção hidráulica de $21 \mathrm{~h}$, não ocorreu remoção e sim aumento da concentração desta.

Como ocorreu a contaminação do RBF pelas bactérias Pseudomonas aeruginosa e Klebsiella pneumoniae e, segundo Stensel et al, apud Sousa (1996) as bactérias do gênero Pseudomonas que são facultativas heterotróficas são capazes de realizar desnitrificação, isso, provavelmente também tenha contribuído para a remoção de nitrato.

As porcentagens de remoção de nitrato no sistema (UASB - RBF), foram: $89,2 \%$ ( $8 \mathrm{~h}$ e $2 \mathrm{~h}) ; 52,5 \%$ ( $8 \mathrm{~h}$ e $1 \mathrm{~h})$; $91,0 \%$ ( $4 \mathrm{~h}$ e $6 \mathrm{~h}$ ); $86,73 \%$ ( $4 \mathrm{~h}$ e $2 \mathrm{~h}$ ); $88,5 \%$ (4h e 1h), o que indicou a efi-ciência do sistema na remoção desta variável.
Na Figura 2 está indicada a variação de nitrato para o sistema UASB-RBF, ao longo das etapas estudadas.

$\mathrm{Na}$ etapa $4 \mathrm{~h}$ e $6 \mathrm{~h}$, ocorreu o melhor percentual de remoção $(9,01 \%)$, enquanto na pesquisa de Sampaio et al (2004), esta foi de $93,0 \%$ no ciclo $10 \mathrm{~h}$ e $2 \mathrm{~h}$, demonstrando mais uma vez influência do TDH em relação ao processo.

\section{Remoção de amônia}

Somente em algumas etapas houve remoção de amônia no reator UASB: $1,27 \%$ ( $8 \mathrm{~h}$ e $2 \mathrm{~h}$ ); $17,5 \%$ ( $8 \mathrm{~h}$ e $1 \mathrm{~h}$ ); $7,1 \%$ (4h e $6 \mathrm{~h}$ ). Observa-se que as remoçôes foram muito reduzidas neste reator. Ocorreu aumento da concentração de nitrato efluente em relação ao afluente nas etapas: $4 \mathrm{~h}$ e $8 \mathrm{~h}(19,5 \%)$, $4 \mathrm{~h}$ e $4 \mathrm{~h}$ $(61,9 \%), 4 \mathrm{~h}$ e $2 \mathrm{~h}(2,0 \%)$ e, $4 \mathrm{~h}$ e $1 \mathrm{~h}$ (30,6\%).

De acordo com Chernicharo (1997), a digestão anaeróbia pode ser considerada como um ecossistema onde diversos grupos de microrganismos tra- 


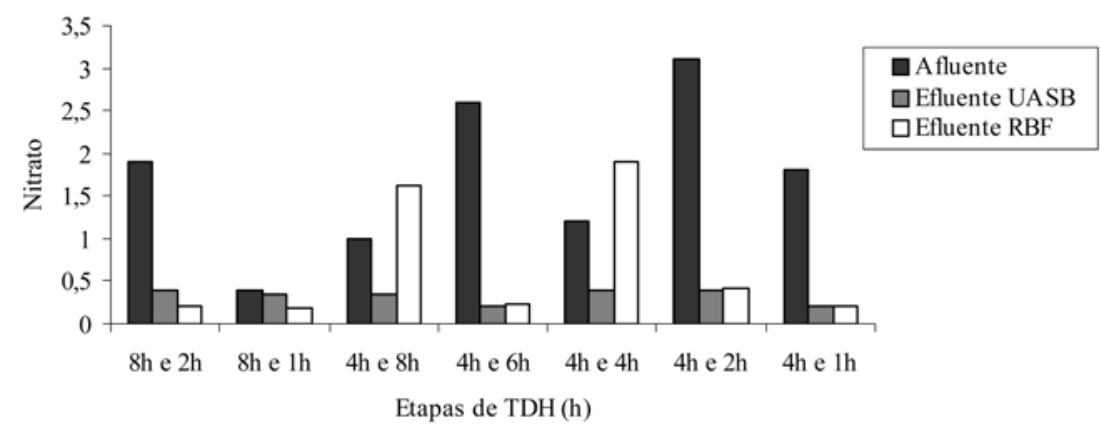

Figura 2 - Variação de nitrato ao longo dos tempos de detenção hidráulica para o sistema UASB-RBF

balham interativamente na conversão da matéria orgânica complexa em metano, gás carbônico, água, gás sulfídrico e amônia, além de novas células bacterianas.

A amônia é, portanto um dos produtos da digestão anaeróbia, o que provavelmente explica o seu aumento em alguns tempos de detenção hidráulica, no reator UASB utilizado nesta pesquisa.

Neste reator, mesmo com a ocorrência de desnitrificação, a qual foi verificada pelo consumo de nitrato, o efluente ainda se apresenta rico em amônia, o que poderia prejudicar a qualidade de um corpo receptor, caso nele ocorresse o seu despejo.

A remoção efetiva de nutrientes é justamente uma das desvantagens do reator UASB e este fato foi observado nesta pesquisa, justificando exatamente a necessidade de um pós-tratamento a esse despejo.

De acordo com Van Haandel e Lettinga (1994) a digestão anaeróbia somente converte o material orgânico, outros constituintes importantes do esgoto (em particular nutrientes e patogênicos) não são afetados de maneira significativa pelo tratamento anaeróbio, sendo necessário a aplicação de um pós-tratamento.

As porcentagens de remoçóes de amônia no RBF, nos tempos de detenção hidráulica em que estas ocorreram foram: 7,4\% (8h e $2 \mathrm{~h}$ ); $62,7 \%$ ( $4 \mathrm{~h}$ e $8 \mathrm{~h}$ ); $37,1 \%$ (4h e $6 \mathrm{~h}$ ); 34,8\% (4h e $2 \mathrm{~h}$ ), nas demais etapas, houve aumento na concentração de amônia: $17,2 \%$ ( 8 h e $1 \mathrm{~h}$ ); 28,3\% (4h e $4 \mathrm{~h}$ ) e $50,6 \%$ ( $4 \mathrm{~h}$ e $1 \mathrm{~h}$ ). A maior remoção encontrada por Sampaio et al (2001) foi de $22 \%$ para o TDH de $1 \mathrm{~h}$ no ciclo (10h e $1 \mathrm{~h}$ ).

Sá (1997) utilizando as espécies fúngicas Aspergillus niger, Aspergillus flavus e Drechslera $s p$, tratando água residuária de indústria de laticínios, observou variações em relação à remoção de amônia em seu experimento, com ocorrência de aumento deste na concentração efluente. As maiores remoções específicas na sua pesquisa foram: $21 \mathrm{~h}(90,0 \%), 11 \mathrm{~h}$ $(70,0 \%), 5 \mathrm{~h}(68,0 \%), 2 \mathrm{~h}(75,0 \%)$. Segundo esta autora, as oscilações de valores para este nutriente podem ter sido geradas por mudanças fisiológicas dos fungos ou ainda por estabelecimento de novas populações microbianas.

De acordo com Cochrane apud Sá (1997), durante as fases de crescimento das espécies fúngicas, existe também retorno de amônia das células para o exterior, refletindo a permeabilidade da célula a este composto. Enzimas, aminoácidos e outros compostos solúveis de nitrogênio também são liberados, denotando desta forma, a dificuldade existente em se definir etapas metabólicas no ecossistema criado no reator, onde populaçóes diferentes se sucedem e partes de micélios antigos são reabsorvidas ou eliminadas.

As porcentagens de remoção de amônia considerando o sistema (UASB $\mathrm{RBF}$ ) desta pesquisa, quando estas ocorreram, foram: $8,5 \%$ ( $8 \mathrm{~h}$ e $2 \mathrm{~h}$ ); $40,6 \%$ ( $4 \mathrm{~h}$ e $8 \mathrm{~h}$ ); $27,6 \%$ ( $4 \mathrm{~h}$ e $6 \mathrm{~h}$ ); $38,3 \%$ ( $4 \mathrm{~h}$ e $2 \mathrm{~h}$ ). Verifica-se que a máxima remoção obtida foi de $40,6 \%$, sendo esta muito baixa, demonstrando que o sistema não se mostrou eficiente na remoção deste parâmetro, devido a pouca eficiência do reator UASB na remoção deste composto, como também na instabilidade das espécies fúngicas em utilizar esta forma de nitrogênio.

Este fenômeno foi também observado no trabalho de Sampaio et al (2004) que obtiveram remoção máxima de $37,0 \%$ no ciclo $12 \mathrm{~h}$ e $1 \mathrm{~h}$.

$\mathrm{Na}$ Figura 3 está indicada a variação de amônia ao longo dos tempos de detenção hidráulica, no sistema UASB-RBF.

\section{Remoção de ortofosfato}

As porcentagens de remoções de ortofosfato no reator UASB foram: $16,0 \%$ ( $8 \mathrm{~h}$ e $2 \mathrm{~h}) ; 4,4 \%$ ( $8 \mathrm{~h}$ e $1 \mathrm{~h})$; $25,1 \%$ ( 4 h e $8 \mathrm{~h}$ ); $22,1 \%$ ( 4 h e $2 \mathrm{~h}$ ). Nos demais tempos de detenção hidráulica observou-se aumento da concentração efluente de ortofosfato em relação à concentração afluente: $10,2 \%$ (4h e $6 \mathrm{~h}$ ), $8,9 \%$ ( 4 h e $4 \mathrm{~h}$ ) e $69,3 \%$ ( $4 \mathrm{~h}$ e $1 \mathrm{~h}$ ).

Observa-se que a eficiência de remoção de ortofosfato neste reator foi muito baixa, o que também foi observado no trabalho realizado por Santaella et al (1999) que obtiveram um máximo de remoção de $12,0 \%$ com 48 horas de tempo de detenção hidráulica e $6,0 \%$ com 6 h de tempo de detenção hidráulica. Aumentos na concentração deste nutriente foram observados em alguns pontos.

Fenômeno semelhante foi observado no trabalho de Rodrigues (1999), onde as maiores reduçóes de ortofosfato foram $32,0 \%$ e $30,0 \%$, correspondentes aos tempos de detenção hidráulica de $5 \mathrm{~h}$ e $11 \mathrm{~h}$ respectivamente.

Comportamento similar foi observado na pesquisa realizada por Sá (1997), sendo que no seu trabalho as remoções

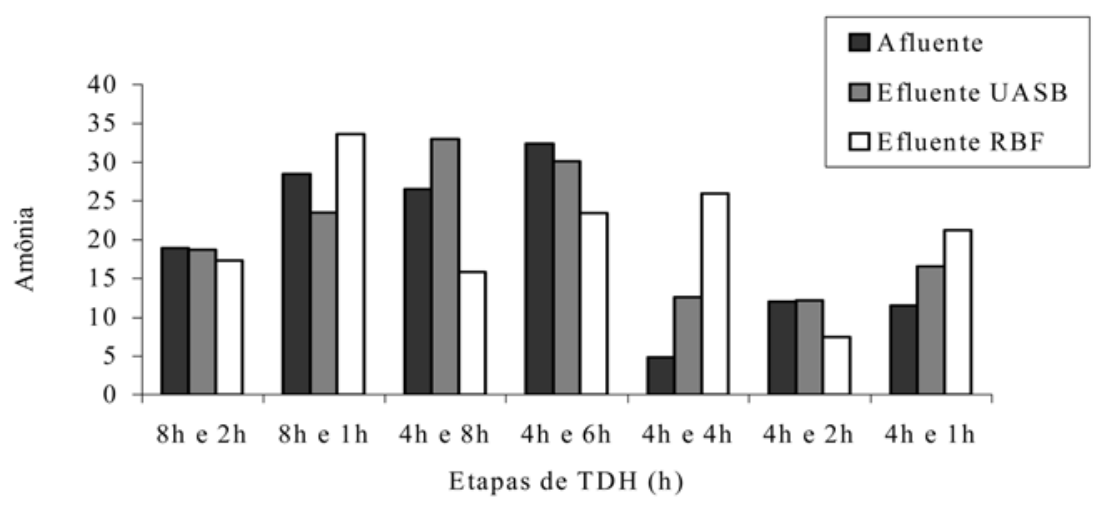

Figura 3 - Variação de amônia ao longo dos tempos de detenção hidráulica para o sistema UASB-RBF 
específicas de ortofosfato foram: $62,0 \%$, $15,0 \%, 63,0 \%, 33,0 \%$ e $54,0 \%$, relativos aos tempos de detenção hidráulica de $31 \mathrm{~h}, 21 \mathrm{~h}, 11 \mathrm{~h}, 5 \mathrm{~h}$ e $2 \mathrm{~h}$, respectivamente.

As porcentagens de remoção no RBF foram: 9,7\% (8h e $2 \mathrm{~h}) ; 11,6 \%$ (8h e $1 \mathrm{~h}$ ); $19,5 \%$ (4h e $8 \mathrm{~h}$ ); $8,8 \%$ (4h e $4 \mathrm{~h}$ ). Nos demais tempos de detenção hidráulica houve aumento da concentração efluente de ortofosfato: $43,1 \%$ ( $4 \mathrm{~h} \mathrm{e} 6 \mathrm{~h}$ ), $5,5 \%$ ( $4 \mathrm{~h}$ e $2 \mathrm{~h}$ ) e $5,7 \%$ ( $4 \mathrm{~h}$ e $1 \mathrm{~h}$ ). Os acúmulos deste nutriente ocorrem provavelmente por processos de quebras de proteínas ou mortes de células antigas.

As remoçôes do sistema para ortofosfato foram: $30,0 \%$ ( $8 \mathrm{~h}$ e $2 \mathrm{~h}$ ), $10,2 \%$ ( 8 h e $1 \mathrm{~h}$ ), $16,4 \%$ ( $4 \mathrm{~h}$ e $8 \mathrm{~h}$ ) e $16,0 \%$ ( $4 \mathrm{~h}$ e $2 \mathrm{~h}$ ), o que demonstra que devido às oscilações e às baixas remoções obtidas no sistema, este não se mostrou eficiente na remoção deste parâmetro. Este fato não ocorreu na pesquisa de Sampaio et al (2004), que observaram remoçôes em todos os ciclos, embora tenha obtido apenas $38,0 \%$ em $12 \mathrm{~h}$ e $1 \mathrm{~h}$.

Na Figura 4 está mostrada a variação de ortofosfato ao longo dos tempos de detenção hidráulica, no sistema UASB-RBF.

\section{Remoção de sólidos suspensos totais (SST)}

No reator UASB as remoções de SST foram: $75,4 \%$ ( $8 \mathrm{~h}$ e $2 \mathrm{~h}$ ), $52,1 \%$ ( 8 h e $1 \mathrm{~h}$ ), $83,6 \%$ (4h e $8 \mathrm{~h}$ ), $86,1 \%$ ( $4 \mathrm{~h}$ e $4 \mathrm{~h}$ ) e $86,3 \%$ ( $4 \mathrm{~h}$ e $1 \mathrm{~h}$ ). As concentraçôes de sólidos suspensos totais nos efluentes foram: $158,4 \mathrm{mg} / \mathrm{L}$ ( $8 \mathrm{~h}$ e $2 \mathrm{~h}$ ), $158,0 \mathrm{mg} / \mathrm{L}$ ( $8 \mathrm{~h}$ e $1 \mathrm{~h}$ ), $77,4 \mathrm{mg} / \mathrm{L}$ ( $4 \mathrm{~h} \mathrm{e}$ $8 \mathrm{~h}), 88,8 \mathrm{mg} / \mathrm{L}$ (4h e $4 \mathrm{~h}$ ) e $47,8 \mathrm{mg} / \mathrm{L}$ (4h e $1 \mathrm{~h}$ ). Observou-se que estas concentrações apresentavam-se ainda bastante elevadas, fazendo-se necessário o uso de um pós-tratamento, a fim de reduzir esta concentração.

No RBF não foi realizada a análise de sólidos suspensos totais, em vista da limpidez do efluente a este reator, indicando a eficiência deste na remoção dos sólidos.

\section{Resultado da análise microbiológica da manta utilizada como meio suporte}

O resultado da análise da manta agulhada de poliamida utilizada como meio suporte no RBF, realizada no Laboratório de Análises Clínicas e Toxicológicas da Universidade Federal do Ceará, indi-

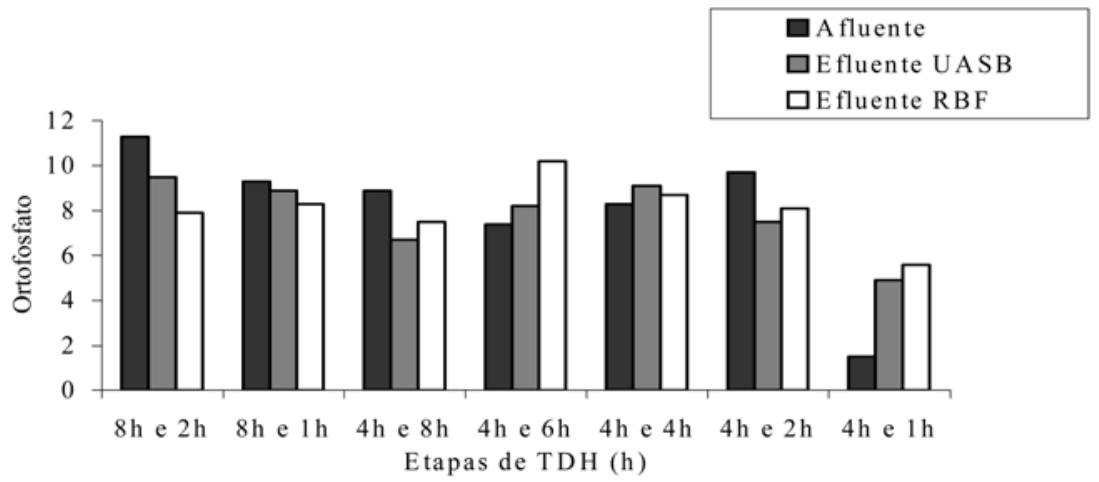

Figura 4 - Variação de ortofosfato ao longo dos tempos de detenção hidráulica, no sistema UASB-RBF

cou a presença das espécies fúngicas Aspergillus flavus e Cladosporium herbarum, como também a contaminação do RBF com as bactérias Pseudomonas aeruginosa e Klebisiella pneumoniae, o que teria sido, provavelmente, evitado pelo uso de um antibiótico associado à acidificação do afluente ao reator.

A espécie Aspergillus niger inoculada neste reator no início do estudo não se manteve ativa. Ocorreu a proliferação da espécie fúngica Aspergillus flavus, uma espécie encontrada no próprio ar e, que talvez tenha se proliferado no reator devido este ter sido montado em local aberto. Como ocorreu a contaminação do RBF pelas bactérias Pseudomonas aeruginosa e Klebsiella pneumoniae e, segundo Stensel et al (1993) apud Sousa (1996), as bactérias do gênero Pseudomonas são facultativas heterotróficas capazes de realizar desnitrificação, isso provavelmente também tenha contribuído para a remoção de nitrato no RBF.

\section{CONCLUSÕES}

A operação em batelada indicou a viabilidade do tratamento de águas residuárias por ação de fungos, embora a remoção mais elevada de DQO tenha sido $45,2 \%$ com tempo de detenção de $8 \mathrm{~d}$.

O reator UASB, quando operado com 4 horas de TDH removeu $82,9 \%$ de DQO, 91,4\% de nitrato e 86,3\% de SST, sendo estas, suas melhores remoções. O reator foi bastante eficiente na remoção destas variáveis, mesmo com baixo tempo de detenção hidráulica.

O reator UASB não se mostrou eficiente na remoção de amônia e ortofosfato, pois em algumas etapas a concentração efluente destas variáveis foi maior que a afluente.
O sistema (UASB - RBF) apresentou remoção de $40,6 \%$ ( $4 \mathrm{~h}$ e $8 \mathrm{~h}$ ) de amônia e 30,0\% (8h e 2h) de ortofosfato, apresentando um efluente ainda rico em relação a estes nutrientes, devido a etapas em que também ocorreu aumento da concentração efluente.

O sistema (UASB - RBF) apresentou remoção de $93,8 \%$ de DQO com TDH de $4 \mathrm{~h}$ no reator UASB e $2 \mathrm{~h}$ no reator biológico com fungos. Remoção de $91,0 \%$ de nitrato foi obtida pelo sistema, com 4 h de TDH no UASB e $6 \mathrm{~h}$ de $\mathrm{TDH}$ no reator biológico com fungos.

Uma combinação que apresentou resultados satisfatórios, levando em conta as remoções obtidas e o baixo TDH foi a etapa de $4 \mathrm{~h}$ e $2 \mathrm{~h}$, apresentando remoçôes de: $93,8 \%$ de DQO; $86,7 \%$ de nitrato; $38,3 \%$ de amônia e $16,0 \%$ de ortofosfato.

Ocorreu, portanto otimização do TDH em relação à pesquisa realizada por Sampaio et al (2004), cujas melhores remoçôes foram $95,0 \%$ de DQO (10h e 4h), 93,0\% de nitrato (10h e $2 \mathrm{~h}$ ), 38,0\% de ortofosfato (12h e $1 \mathrm{~h}$ ) e $37,0 \%$ de amônia (12h e $1 \mathrm{~h}$ ).

\section{REFERÊNCIAS}

BOLDÚ, F. X. P. Growth of on aromatic hydrocarbons. Environmental technology perspectives. Thesis Wageningen University, Wagenningen, The Netherlands, 2002.

CHERNICHARO, C. A. L. Reatores anaeróbios. Belo Horizonte, Departamento de Engenharia sanitária e Ambiental, UFMG, 1997.

MACHADAR, I. et al. A novel and cost-effective sewage treatment system consisting of UASB pre-treatment and aerobic post-treatment units for developing countries. Water Science and technology, v. 36, n.12, p. 189-197, 1997.

METCALF \& EDDY. Wastewater Engineering: treatment, disposal and reuse. $3^{\mathrm{a}} \mathrm{ed}$. NewYork:McGrawHill, 822p. 1991. 
RABELO, S. M. Viabilidade do processo de lodo ativado aplicado ao tratamento da água residuária de uma indústria de beneficiamento de castanha de caju. Fortaleza. Dissertação (Mestrado em Engenharia Civil, área de concentração em Saneamento Ambiental, Universidade Federal do Ceará), 98p. 1999.

RODRIGUES, K. de A. Tratamento biológico de áoua residuária sintética de laticinios por de composição fúngica. Fortaleza, Dissertação (Mestrado em Engenharia Civil, área de concentração em Saneamento Ambiental, Universidade Federal do Ceará), 113p. 1999.

SÁ, I.M.B. Biotratamento de efluente de uma indústria de laticinios por ação de fungos decompositores. Fortaleza. Dissertação (mestrado) - Universidade Federal do Ceará, 83p. 1997.

SAMPAIO, G. M. et al. Pós-Tratamento de efluente de um reator UASB através de um reator biológico com fungos. Revista Engenharia Sanitária e Ambiental, v.9, n.1, p.73-81, jan./mar. 2004 .

SANTAELLA, S. T. Estudos de tecnologias apropriadas para tratamento de efluentes da indústria de castanha de caju. Fortaleza: UFC, Departamento de Engenharia Hidráulica e Ambiental. (Relatório Institucional de Pesquisa), 31p. 1997.

SANTAELLA, S. T. Estudos de tecnologias apropriadas para tratamento de efluentes da indústria de castanha de caju. Fortaleza: UFC, Departamento de Engenharia Hidráulica e Ambiental. (Relatório Institucional de Pesquisa), 31p. 1999.

SOUSA, J. T. Pós-tratamento de efluente de reator anaeróbio de fluxo ascendente em reator aeróbio seqüencial em batelada e coluna de lodo anaeróbio para desnitrificação. São Paulo, Tese (doutorado) - Universidade de São Paulo. Escola de Engenharia de São Carlos, 258p. 1996.

VAN HAANDEL, A. O.; LETTINGA, O. Tratamento anaeróbio de esgotos: um manual para regióes de clima quente. Campina Grande: Epgraf, 239p. 1994.

\section{Endereço para correspondência:}

\section{Emília Maria Alves Santos}

Departamento de Engenharia

Hidráulica e Ambiental

Universidade Federal do Ceará

Campus do Pici - Bloco 7 I 3

6045 I-970 - Fortaleza - CE - Brasil

Tel: (85) 40089774

E-mail: florema@bol.com.br
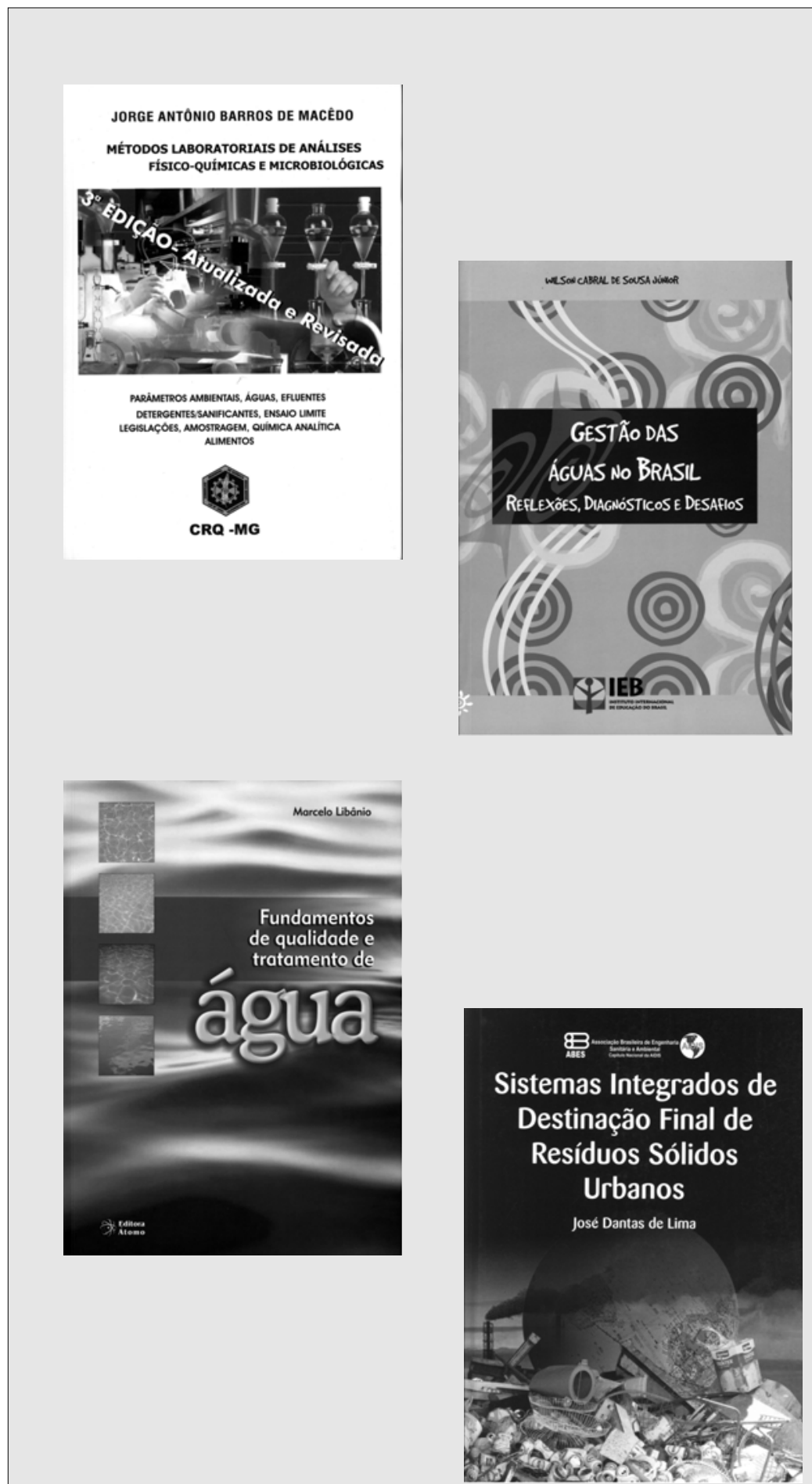

\section{FUNDO EDITORIAL ABES}

\author{
livraria@abes-dn.org.br
}

